ISSN 1012-277X S.Afr.J.Ind.Eng. $-66-$

S A Journal c6 Industrial Engineering, Vol 5, No 2, December 1992, pp.66-80 鵕

PRAKTIESE DRIEDIMENSIONELE SIRKEL-INTERPOLASIE VIR NUMERIESBEHEERDE MASJIENE

\title{
A J IUBBE
}

\section{Departement Bedryfs- en Sisteemingenieurswese}

\section{Universiteit van Pretoria}

\section{OPSOMMING}

Numeriesbeheerde vervaardigingsmasjiene mak voorsiening vir die sny van sirkels in slegs twee dimensies. Hierdie beperking veroorsaak dat 'n wye reeks vorme slegs m.b.v. rekenaargesteunde ontwerpprogrammatuur gesny kan word. In hierdie artikel word die teorie afgelei en 'n subroetine ontwikkel waarmee driedimensionele sirkel-interpolasie met radiuskorreksie vir praktykgebruik beskikbaar gestel word.

\section{ABSTRACT}

Numerically controlled manufacturing machines provide for machining circles only in two dimensions. As a result of this limitation a wide variety of shapes can only be machined by making use of computer-aided design. In this article the theory is derived and a subroutine developed with which three dimensional circular interpolation with radius correction is made available for application in practice. 


\section{INLEIDING}

Driedimensionele numeriesbeheerde masjiene kan lineêre bewegings in drie asse gelyktydig uitvoer. Sirkelvormige snyerbewegings m.b.v. sirkel-interpolasie kan egter slegs tweedimensioneel uitgevoer word. vir sirkelvormige beweging is driedimensionele masjiene in effek slegs tweeen-'n-halfdimensioneel waar twee-en-'n-half-dimensioneel beteken dat enige twee van die moontlike drie asse gelyktydig kan beweeg.

Dit dien gelet te word dat met heliese-interpolasie ' $n$ sirkelbeweging gelyktydig met 'n lineêre beweging uitgevoer word, maar die resulterende beweging is spiralvormig en nie sirkelvormig nie. Heliese- interpolasie is dus NIE dieselfde as driedimensionele sirkel-interpolasie nie.

Die redes vir bogenoemde beperking $t .0 . v$. sirkelbeweging is die volgende:-

a) Die berekening van punte op die omtrek van 'n sirkel met die normale wiskundige uitdrukkings nl

$$
\text { of } \begin{aligned}
& x^{2}+y^{2}= \\
& x=r \cos \theta \\
& y=r \sin \theta
\end{aligned}
$$

is 'n te stadige proses. Vir punte baie naby aan mekaar op die omtrek van ' $\mathrm{n}$ sirkel, kan 'n normale rekenaar (soos gebruik in numeriese beheer) die punte nie vinnig genoeg genereer om te verseker dat die snyer kontinu beweeg nie. Vir tweedimensionele sirkels is wiskundige soekprosedures ontwikkel waarmee punte baie vinnig gegenereer kan word en hierdie soekprosedures word algemeen gebruik vir sirkelinterpolasie in numeriesbeheerde masjiene. Sodanige soekprosedures is nie vir driedimensionele sirkels ontwikkel nie.

b) Al die gegewens wat benodig word om 'n driedimensionele sirkel te beskryf, soos bv. die loodregte 
vektor op die sirkelvlak is nie altyd geredelik beskikbaar nie. Dit is nie vir die programmeerder van numeriesbeheerde masjiene 'n eenvoudige taak (soos vir tweedimensionele sirkels) om 'n driedimensionele sirkel vanaf 'n werkstekening wiskundig te beskryf nie.

Die enigste praktiese oplossing vir die probleem tot dusver, is om van 'n rekenaar gebruik te maak om die punte te genereer en dan die koördinatpunte in die beheer van die numeriesbeheerde masjien in te lees.

\section{ALGEMENE GEBRUIK VAN DRIEDIMENSIONELE SIRKELS}

Daar is verskeie toepassings vir driedimensionele sirkelinterpolasie met numeriesbeheerde freesmasjiene waar berekeningspoed onbelangrik is. Die belangrikste gebruik hiervan is vir die afronding van randte van plat vlakke wat teen 'n helling staan. Sulke afrondingsvlakke word gevorm soos getoon in Figuur 1 .

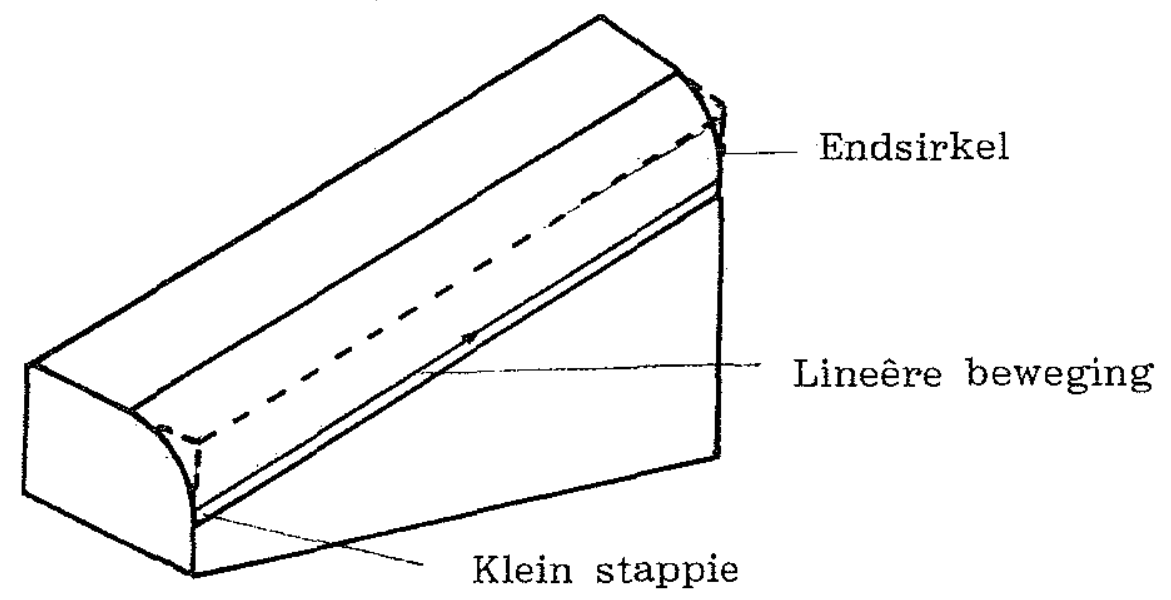

\section{Afronding van 'n rand FIGUUR 1}

'n Klein stappie op die omtrek van die sirkel word gevolg deur 'n lineêre beweging al langs die rand tot by die endsirkel. Terwyl die lineêre beweging uitgevoer word, word die volgende punt op die omtrek van die tweede sirkel reeds bereken. 
Wanneer die berekening van 'n volgende punt op die omtrek van 'n sirkel voorafgegaan word deur 'n lineêre of normale tweedimensionele sirkelbeweging, is berekeningspoed nie 'n faktor wat in ag geneem moet word nie. In sulke gevalle is die beskrywing van die driedimensionele sirkel eerder as die berekeningspoed die beperkende faktor.

In hierdie artikel word 'n algoritme ontwikkel waarmee driedimensionele sirkel-interpolasie gedoen kan word. Ook word ' $n$ metode voorgestel waarmee die beskrywing van driedimensionele sirkels grootliks vereenvoudig word. Verder word 'n program vir die MAH0-432 numeriesbeheerdefreesmasjien geskryf wat as subroetine gebruik kan word om enige driedimensionele lineêre afronding te sny.

\section{AIGORITME VIR DRIEDIMENSIONELE SIRKEL-INTERPOLASIE}

Enige driedimensionele (3D) sirkel kan m.b.v. twee rotasiebewegings geroteer word na 'n tweedimensionele (2D)

sirkel. Dus kan 'n spesifieke $2 \mathrm{D}-\mathrm{sirkel}$ na twee rotasiebewegings altyd 'n spesifieke 3D-sirkel verteenwoordig.

In Figuur 2 hieronder word 'n 2D-punt met koördinaatwaardes $x$ en $y$ deur 'n hoek $\theta$ om die $z$-as geroteer. Vir 'n regterhandse 3D-koördinaatstelsel is die konvensie dat' $n$ positiewe rotasie sodanig is dat wanneer vanaf 'n positiewe as na die oorsprong gekyk word, 'n $90^{\circ}$ antikloksgewyse rotasie een positiewe as na 'n ander sal transformeer. So sal 'n $90^{\circ}$ antikloksgewyse rotasie van die positiewe $x$-as rondom die $z$-as die $x$-as roteer na die positiewe $y$-as.

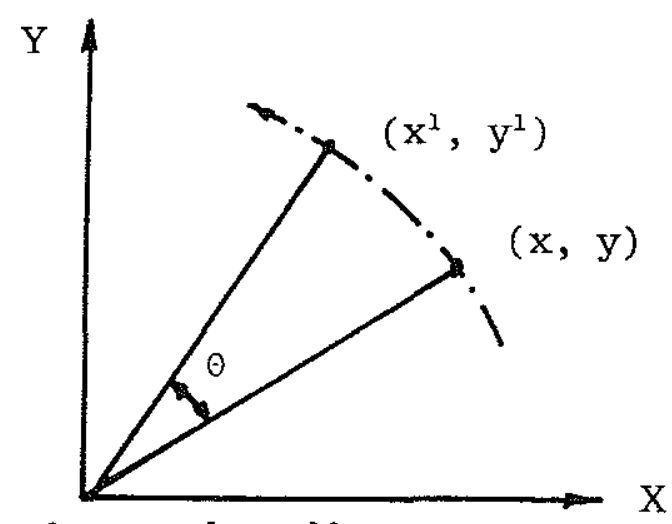

Rotasie rondom die $z$-as 
Die rotasie word wiskundig soos volg uitgedruk.

$$
\begin{aligned}
& x^{1}=x \cos \theta-y \sin \theta \\
& y^{1}=x \sin \theta+y \cos \theta .
\end{aligned}
$$

waar

$$
x^{1} \text { en } y^{1} \text { die geroteerde koördinate, }
$$$$
x \text { en } y \text { die oorspronklike koördinate }
$$$$
\text { en } \theta \text { die hoek is waardeur die punt om die z-as }
$$
geroteer word

In matriksvorm is $\mathrm{vgl} \mathrm{(1):}$

$$
\begin{aligned}
& {\left[\begin{array}{ll}
x^{1} & y^{1}
\end{array}\right]=\left[\begin{array}{ll}
x & y
\end{array}\right] \cdot\left[\begin{array}{cc}
\cos \theta & \sin \theta \\
-\sin \theta & \cos \theta
\end{array}\right]} \\
& \text { of } P^{1} \quad=P \cdot R
\end{aligned}
$$

$$
\begin{aligned}
\text { waar } & P \\
P^{1} & \text { die puntmatriks, } \\
R & \text { die reroteerde puntmatriks en }
\end{aligned}
$$

Die 2D-rotasie van vgl (2) kan ook die eerste rotasie van 'n 3D-rotasie wees en sal in so 'n geval soos volg voorgestel kan word

$$
R_{z}(\theta)=\left[\begin{array}{ccc}
\cos \theta & \sin \theta & 0 \\
-\sin \theta & \cos \theta & 0 \\
0 & 0 & 1
\end{array}\right]
$$

waar $R_{z}(\theta)$ die rotasiematriks om die z-as in drie dimensies verteenwoordig.

$\mathrm{Vgl}$ (4) kan maklik geverifieer word deur 'n rotasie van $90^{\circ}$ van bv $\left[\begin{array}{lll}0 & 1 & 0\end{array}\right]$, wat 'n eenheidsvektor in die rigting van die $y$-as verteenwoordig na $\left[\begin{array}{lll}-1 & 0 & 0\end{array}\right]$ wat ' $n$ eenheidsvektor in die rigting van die negatiewe $x$-as verteenwoordig. 
As die volgende produk ge-evalueer word

$$
\left[\begin{array}{lll}
0 & 1 & 0
\end{array}\right] \cdot\left[\begin{array}{rrr}
0 & 1 & 0 \\
-1 & 0 & 0 \\
0 & 0 & 1
\end{array}\right]
$$

word die verwagte waarde $\left[\begin{array}{lll}-1 & 0 & 0\end{array}\right]$ inderdaad verkry.

Op soortgelyke wyse word die rotasiematriks om die $y$-as verkxy nl.

$$
R y(\phi)=\left[\begin{array}{ccc}
\cos \phi & 0 & -\sin \phi \\
0 & 1 & 0 \\
\sin \phi & 0 & \cos \phi
\end{array}\right]
$$

waar $\phi$ die hoek is waardeur 'n driedimensionele punt om die $y$-as geroteer word.

'n Driedimensionele punt wat eers deur $\theta$ grade om die z-as en dan $\phi$ grade om die $y$-as geroteer word, sal dje volgende rotasiematriks oplewer.

$$
\mathrm{R}_{\mathrm{A}}=\left[\begin{array}{lll}
r_{11} & r_{12} & r_{13} \\
r_{21} & r_{22} & r_{23} \\
r_{31} & r_{32} & r_{33}
\end{array}\right]
$$

waar $R_{A}$ die gekombineerde rotasiematriks en

$$
\begin{aligned}
& r_{11}=\cos \theta \cos \phi \\
& r_{12}=-\sin \theta \\
& r_{13}=-\cos \theta \sin \phi \\
& r_{21}=\sin \theta \cos \phi \\
& r_{22}=\cos \theta \\
& r_{23}=\sin \theta \sin \phi \\
& r_{31}=0 \\
& r_{32}=\sin \phi \\
& r_{33}=\cos \phi
\end{aligned}
$$


Die koördinaatmatriks vir so 'n punt is

$\left[\begin{array}{lll}x^{1} & y^{1} & z^{1}\end{array}\right]=\left[\begin{array}{lll}x & y & z\end{array}\right] \cdot R_{A}$

war $\left[\begin{array}{lll}x & y & z\end{array}\right]$ die oorspronklike puntmatriks

en $\quad\left[\begin{array}{lll}x^{1} & y^{1} & z^{1}\end{array}\right]$ die dubbelgeroteerde puntmatriks is.

Deur vgl (6) toe te pas op al die punte op die omtrek van 'n 2D-sirkel op die $y-z-v l a k$, word punte op die omtrek van 'n 3D-sirkel verkry. 3D-interpolasie word verkry deur hierdie punte met reguit lyntjies te verbind. Hoe meer punte op die omtrek van die sirkel bereken word, hoe gladder sal die sirkel gevorm word.

\section{SNY VAN 'N 3D-SIRKEL}

3D-snywerk op 'n freesmasjien word altyd met 'n balneussnyer gedoen. Die radiuskorreksiefunksie van numeriesbeheerde freesmasjiene is slegs van toepassing op 2D-werk. Vir enige $3 \mathrm{D}$-werk moet die programmeerder self snyerradiuskorreksie in ag neem.

Vir die sny van 'n 3D-sirkel kan snyerradiuskorreksie soos volg in berekening gebring word.

Gestel ' $n$ sirkel met radius $R$ moet gesny word met ' $n$ balneussnyer met radius $r$. 'n punt op die omtrek van die 2Dsirkel met radiuskorreksie kan soos volg beskryf word.

$$
\begin{aligned}
& z=(R+r) \cos \Psi \text { en } \\
& y=(R+r) \sin \Psi \text { waar }
\end{aligned}
$$

$z$ en $y$ die afstande vanaf die sirkelsenter in die $z$ - en $Y$ - rigting is, en $\Psi$ die sirkelhoek is, soos getoon in Figuur 3 .

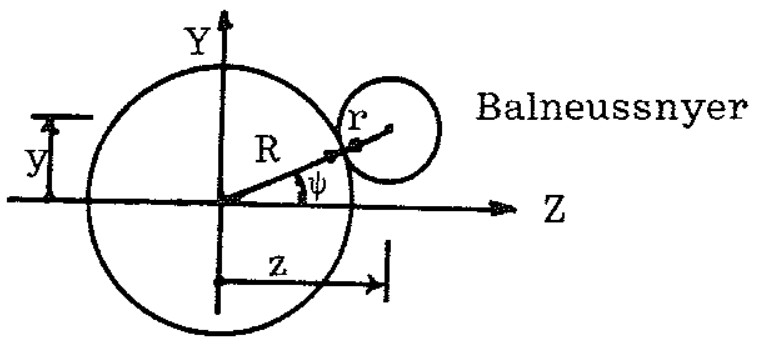

'n punt op die omtrek van 'n 2D-sirkel met radiuskorreksie 
As hierdie punt nou m.b.v. vgl (6) geroteer word, word 'n punt met radiuskorreksie op die omtrek van 'n 3D-sirkel verkry. Vir 3D-sirkel-interpolasie met radiuskorreksie word die z-en-y-waardes van $\mathrm{vgl}$ (6) vervang met $\mathrm{vgl}$ (7) en T neem sodanige waardes aan dat genoegsame punte vir 'n gladde sirkel verseker word.

\section{BESKRYWING VAN ' $N$ 3D-SIRKEL}

In die voorafgaande gedeelte is die nodige wiskundige afleiding gedoen om 'n 2D-sirkel na 'n 3D-sirkel te roteer. In praktyk is dit egter selde die geval dat die 2D-beskrywing plus die nodige rotasies vir 'n 3D-sirkel beskikbaar is. Die vernaamste rede hiervoor is dat tweedimensionele werkstekeninge nie volledig 3D-gegewens aantoon nie. So word normaalweg op ' $n$ tekening slegs aangedui dat 'n sekere hoek afgerond moet word met 'n bepaalde radius.

Sou bv. die volgende gegewens op 'n werkstekening beskikbaar wees, is dit moontlik om die nodige wiskundige berekeninge deur te voer om 'n 3D-sirkel volledig te beskryf.

1. Koördinate van die middelpunt plus die koördinate van twee punte op die omtrek.

2. Koördinate van drie punte op die omtrek.

3. Koördinate van die middelpunt, die radius en die loodregte vektor op die sirkelvlak.

4. Koördinate van twee punte op die omtrek, die radius plus die loodregte vektor op die sirkelvlak.

Om die probleem van gebrekkige gegewens te ondervang, kan 'n indirekte metode waarvoor gegewens reeds bekend is, suksesvol gebruik word om 'n 3D-sirkel te beskryf.

Wanneer ' $n$ 3D-hoek, soos getoon in Figuur 4, afgerond moet word met ' $\mathrm{n}$ radius $\mathrm{R}$, dan is die koördinate van die twee hoekpunte altyd beskikbaar. 


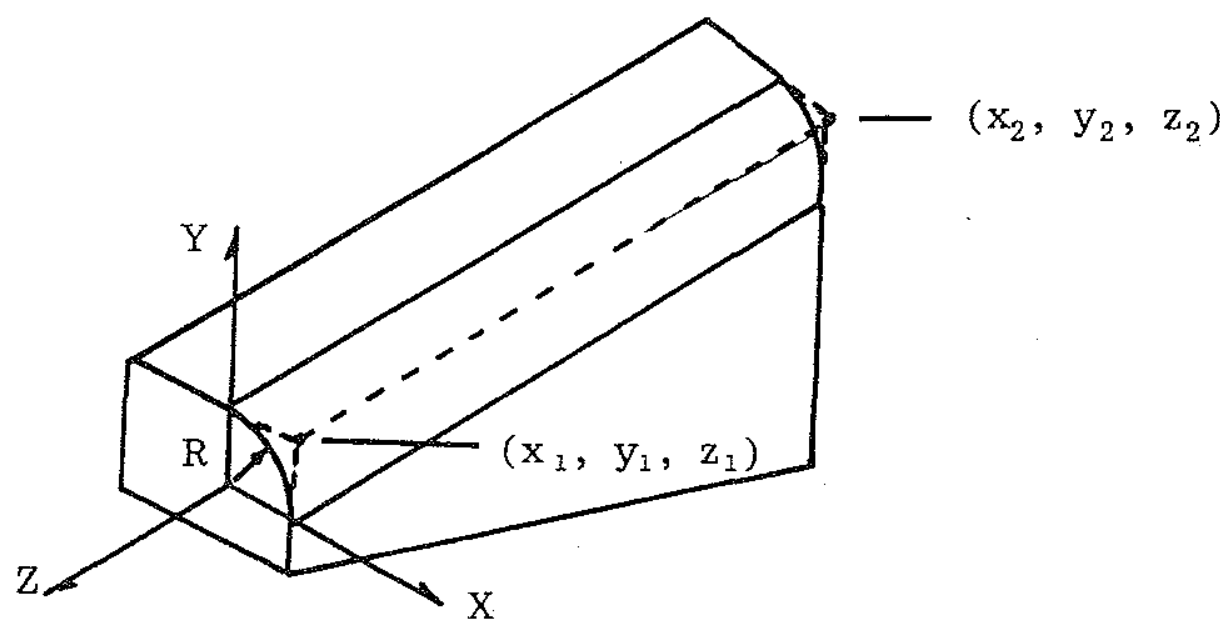

Afronding van 'n 3D-rand

FIGUUR 4

Uit die geometrie van Figuur 4 is dit duidelik dat genoegsame. gegewens wel beskikbaar is sodat dit moontlik is om die koördinate van die middelpunt asook die loodregte vektor op die sirkelvlak, te bereken. M.b.v. die loodregte vektor, kan die twee rotasiehoeke wat vir vgl (6) benodig word, afgelei word. Alle gegewens wat nodig is om die 3Dsirkels te beskryf, kan dus verkry word.

\section{BEREKENING VAN ROTASIEHOEKE}

Gestel die koördinate van die twee hoekpunte (Figuur 4 ) is $x_{1}, Y_{1}, z_{1}$ en $x_{2}, Y_{2}$ en $z_{2}$ dan is

$$
\begin{aligned}
& \theta=\operatorname{Tan}^{-1} \frac{y_{2}-y_{1}}{x_{2}-x_{1}} \\
& \phi=\operatorname{Tan}^{-1} \frac{z_{1}-z_{2}}{x_{2}-x_{1}}
\end{aligned}
$$

en

war $\theta$ en $\phi$ die hoeke in die rotasiematriks van vgl (5) is.

\section{BERERENING VAN KOÖRDINATE VAN MIDDELPUNT}

Figuur 4 toon ' $n$ afronding in die lste kwadrant. Om voorsiening te mak vir afronding in enige kwadrant word die 
afstand van die middelpunt vanaf enige hoekpunt (kyk Figuur 5) soos volg bereken.

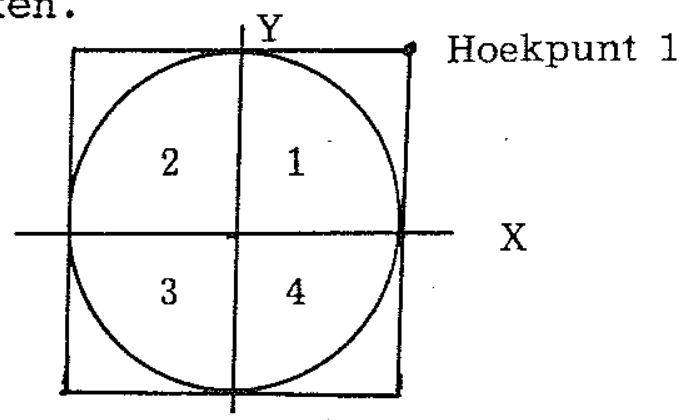

\section{Afronding in vier kwadrante \\ FIGUUR 5}

Vir kwadrant 1 geld

$\left[\begin{array}{lll}\mathrm{x}_{1}^{1} & \mathrm{y}_{1}^{1} & \mathrm{z}_{1}^{1}\end{array}\right]=\left[\begin{array}{lll}0 & \mathrm{R} & \mathrm{R}\end{array}\right] \cdot \mathrm{R}_{\mathrm{A}}$

waar

$\mathrm{x}^{1}{ }_{1}, \mathrm{y}_{1}{ }_{1}$ en $\mathrm{z}_{1}{ }_{1}$ die $\mathrm{x}-, \mathrm{y}$ - en $\mathrm{z}$-afstande in drie dimensies is wat die sirkelmiddelpunt vanaf hoekpunt 1 is,

$R_{A}$ die rotasiematriks is en
$R$ die radius van die sirkel is.

Soortgelyke uitdrukkings geld respektiewelik vir kwadrante 2,3 en 4

$$
\begin{aligned}
& {\left[\begin{array}{lll}
x_{2}^{1} & y_{2}^{1} & z_{2}^{1}
\end{array}\right] \quad=\left[\begin{array}{lll}
0 & R & -R
\end{array}\right] \cdot R_{A}} \\
& {\left[\begin{array}{lll}
x_{3}^{1} & y_{3}^{1} & z^{1}{ }_{3}
\end{array}\right]=\left[\begin{array}{lll}
0 & -R & -R
\end{array}\right] \cdot R_{A}}
\end{aligned}
$$

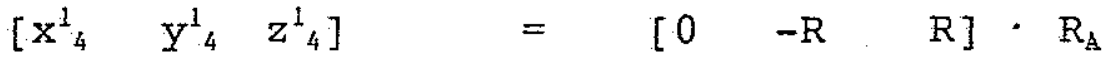

waar $\mathrm{x}^{1}{ }_{2}$ die $\mathrm{x}$-afstand is wat die sirkelmiddelpunt vanaf hoekpunt 2 is, ens.

Dit dien daarop gelet te word dat die hoekpunte van die kwadrant wat afgerond moet word se koördinate in terme van absolute waardes t.o.v. enige nulpunt verskaf word. Die sirkelmiddelpunt se koördinate daarenteen word bereken as inkrementele waardes vanaf die hoekpunt. Die rotasiematriks $R_{A}$ is afgelei vir rotasie rondom die nulpunt. Deur die $x$ - en $y$-waardes egter volgens vgl (7) te bereken, bete- 
ken dit dat 'n rotasie altyd om die sirkelmiddelpunt plaasvind. Die driedimensionele sirkel se koördinate sal dus altyd in absoluut vanaf die nulpunt bereken word as vgl (6) se koördinaatwaardes by die sirkelmiddelpunt se waardes bygetel word.

Die koördinate van 'n punt op die omtrek van 'n 3D-sirkel is dus

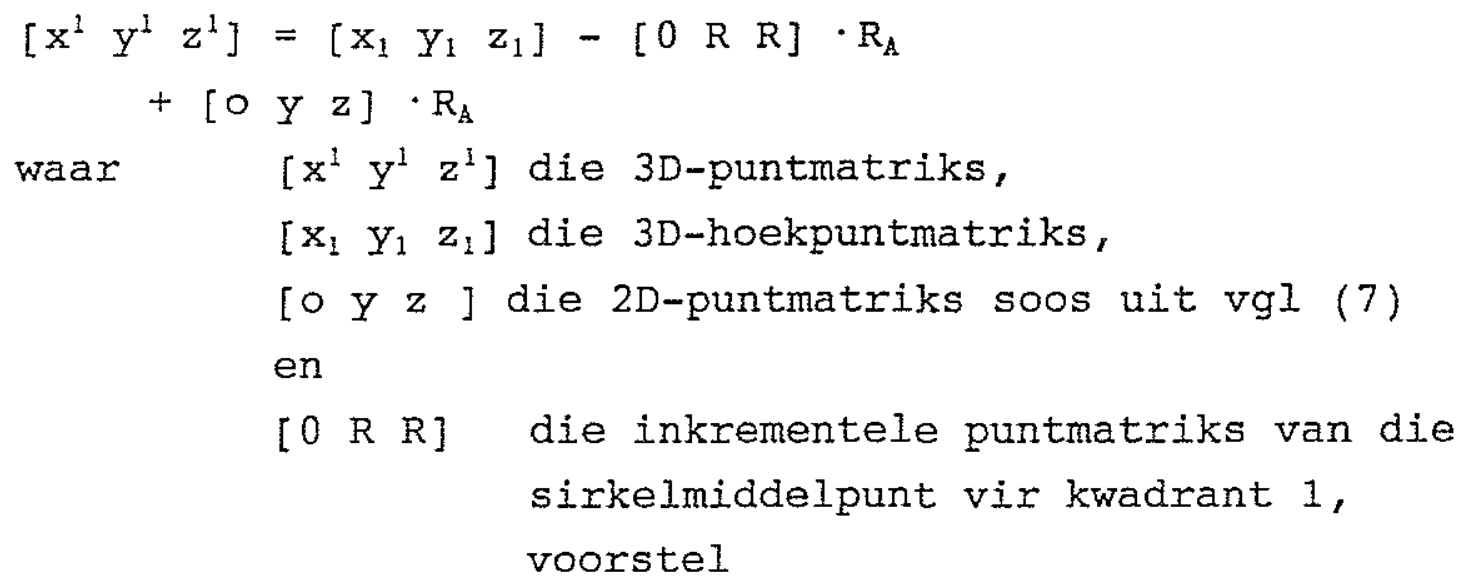

Op soortgelyke wyse kan punte ook op die omtrek van die endsirkel (Figuur 4) bereken word. Wanneer ooreenstemmende punte op die twee sirkels verbind word, word 'n 3D-silinder verkry. Vir afronding hoef slegs een van die kwadrante van die silinder bereken te word. As die radius van die twee sirkels verskil, word koniese afronding outomaties verkry.

Snyerradiuskorreksie vir snywerk op die $x-y$-vlak word vir kwadrante 1 en 4 bygetel omdat dit buite-afronding verteenwoordig. Vir kwadrante 2 en 3 word radiuskorreksie afgetrek omdat binne-afronding verkry word (Kyk Figuur 6).

2

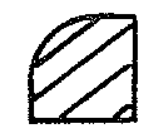

3

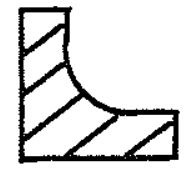

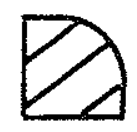

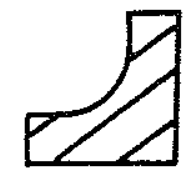

Kwadrant 1 (Buite)

Kwadrant 4

(Binne)

\section{Binne- en buite-afronding}

FIGUUR 6 


\section{PROGRAM VIR 3D-SIRKEL-INTERPOLASIE EN AFRONDING}

Die onderstaande program is geskryf in MAHO-kode. 'n Keuse kan uitgeoefen word ten opsigte van die kwadrant waarin afgerond word. Afronding geskied altyd deur 'n hoek van $90^{\circ}$. Dit is moontlik om die parameterprogram te verander sodat afronding ook deur hoeke anders as 90 kan geskied. (E100 is beginhoek en $\mathrm{E90}$ is endhoek). Snyerradiuskorreksie word outomaties in ag geneem.

Indien slegs 'n 3D-sirkel en nie 'n afronding gesny moet word, kan die hoekpunt van die tweede sirkel op 'n afstand van 'n paar mikromillimeters vanaf die eerste sirkelhoekpunt gegee word om die vlak van die sirkel aan te dui. Die twee sirkels val dan vir alle praktiese doeleindes op mekar.

As invoer vir onderstaande program, word die volgende gegewens benodig.

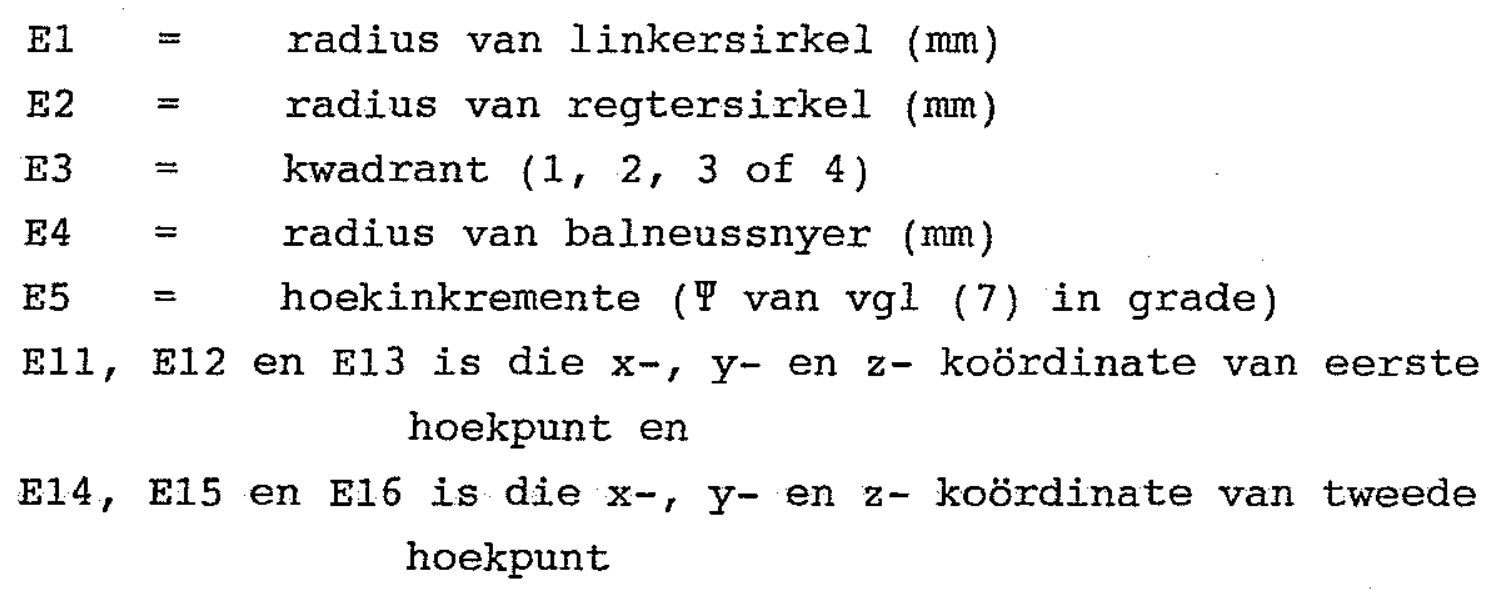

8. PM9 7006

N1 G18 F1000 S1000 T1 M66

N2 G54 M3

N3 $E I=20$ (Radius van eerste sirkel)

N4 E2=20 (Radius van tweede sirkel)

N5 E3=1 (Kwadrant $1,2,3$ of 4 )

N6 $E 4=5$ (Radius van balneussnyer)

N7 $E 5=5$ (Hoekinkrement in grade)

N8 (Die volgende drie waardes is die $x-, y$ - en $z$-waardes van die eerste hoekpunt) 


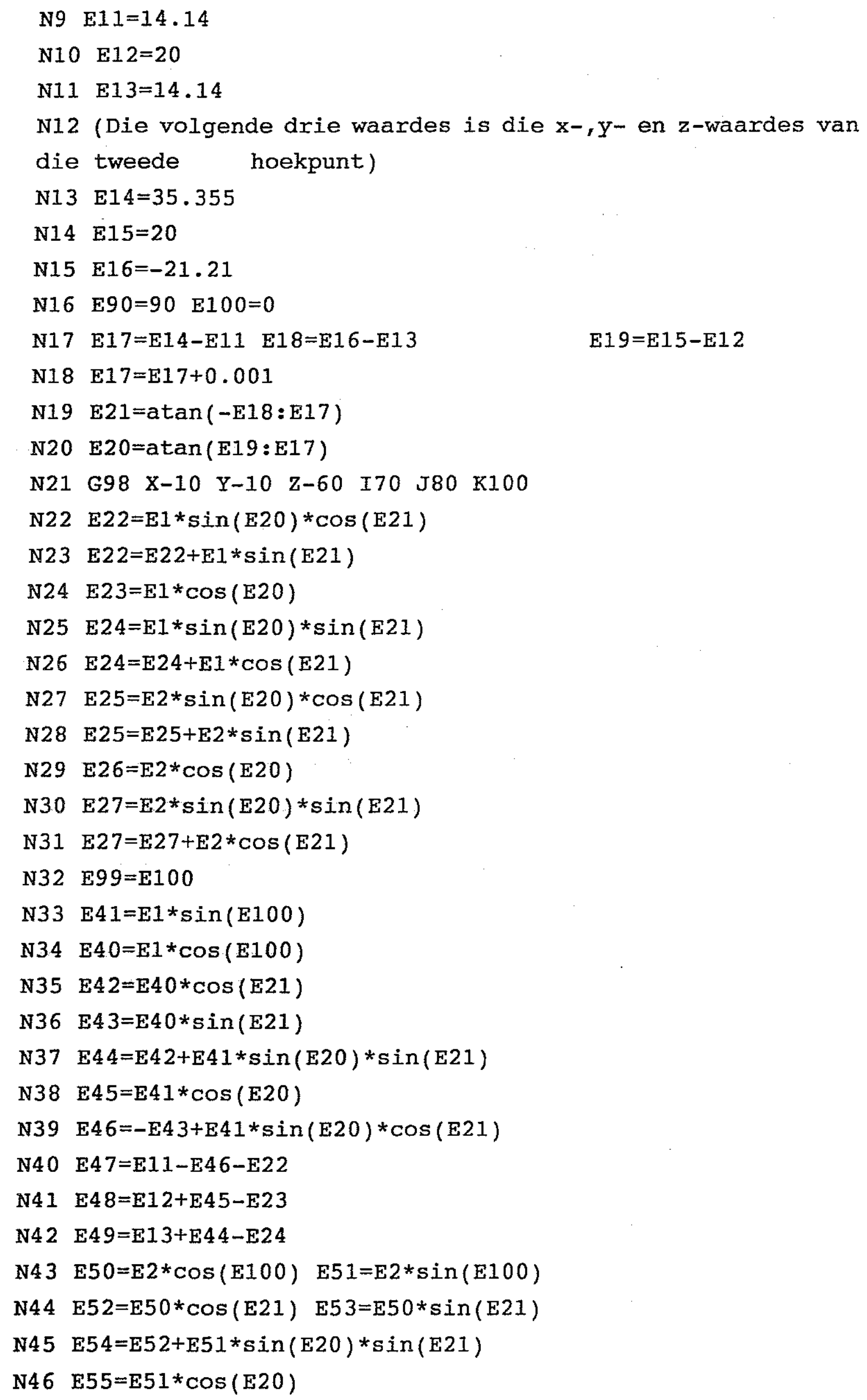




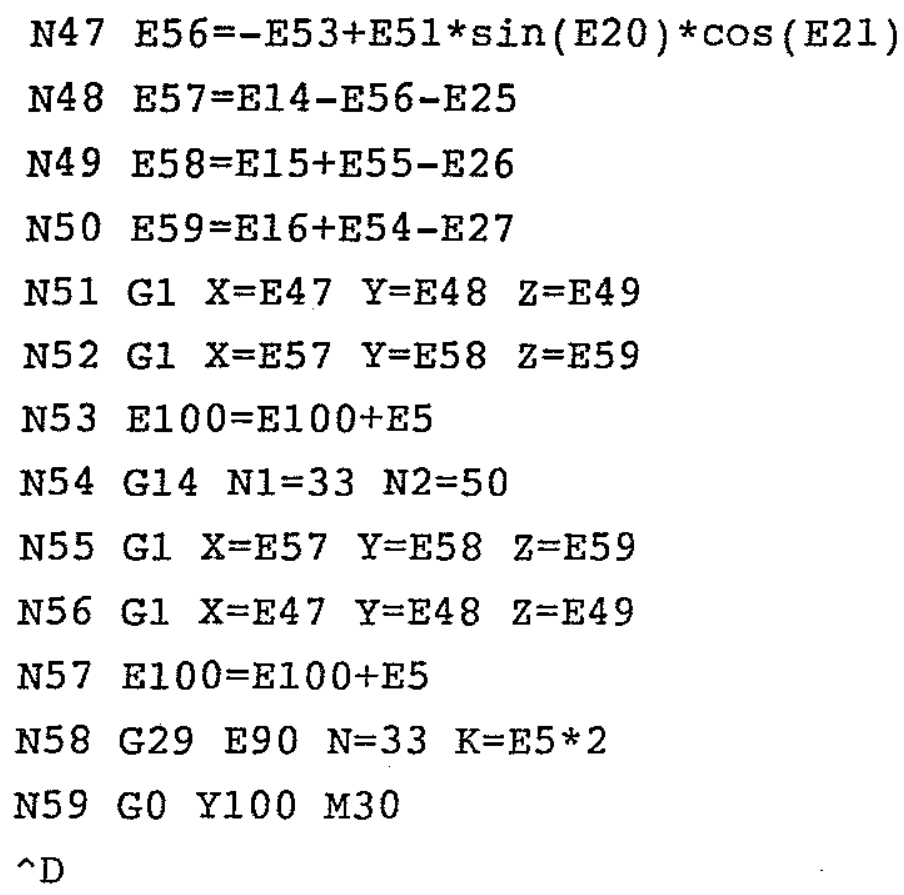

9. WAARDESKATTING

Bevestiging is van die vervaardiger MAHO in Duitsland verkry dat hierdie die eerste beskikbaargestelde subroetine is waarmee driedimensionele sirkel-interpolasie vir MAHO-masjiene moontlik gemaak word.

Die program wat in MAHo-format geskryf is, kan gexedelik omgeskakel word na die format van enige ander masjien wat toegerus is vir parameterprogrammering.

Die tegniek van driedimensionele sirkel-interpolasie het wye toepassingsmoontlikhede en kan 'n belangrike leemte in veral die plastiekinspuit en gieterybedrywe vul. 
10. BRONNELYS

1. Foley, J.D., FUNDAMENTALS OF INTERACTIVE COMPUTER GRAPHICS, Addison-Wesley, 1984

2. Thomas, G.B., CALCULUS AND ANALYTIC GEOMETRY, AddisonWesley, 1962

3. Chasen, S.H., GEOMETRIC PRINCIPLES AND PROCEDURES FOR COMPUTER GRAPHIC APPLICATIONS, Prentice-Hall, 1978

4. Winston, W.L., OPERATIONS RESEARCH : APPLICATIONS AND ALGORITHMS, Duxbury Press, 1987

5. MAHO Aktiengeselischaft, PROGRAMMIER- UND BEDIENUNGSANLEITUNG, MAHO A.G., Pfronten, 1988

6. Lubbe, A.J., DIE ONTWIKKELING VAN ' $N$ PARAMETRIESE MODEL VIR DIE SNY VAN RUIMTES SOOS DIÉ VAN MARGARIENBAKKIES, $S$ A Journal of Industrial Engineering, Vol. 4, No 2, December 1990. 